\title{
Asymmetric Homogeneous Hydrogenation of 2-Pyridones
}

\author{
Jędrzej Wysocki ${ }^{\mathrm{a}, \mathrm{b}}$ \\ Christoph Schlepphorst ${ }^{a}$ \\ Frank Glorius*a \\ a Organisch-Chemisches Institut, Westfälische Wilhelms-Universität \\ Münster, Corrensstr. 40, 48149 Münster, Germany \\ glorius@uni-muenster.de \\ b NRW Graduate School of Chemistry, Wilhelm-Klemm-Str. 10, \\ 48149 Münster, Germany \\ Dedicated to Peter Vollhardt for all the inspiration he has given the \\ chemistry world
}

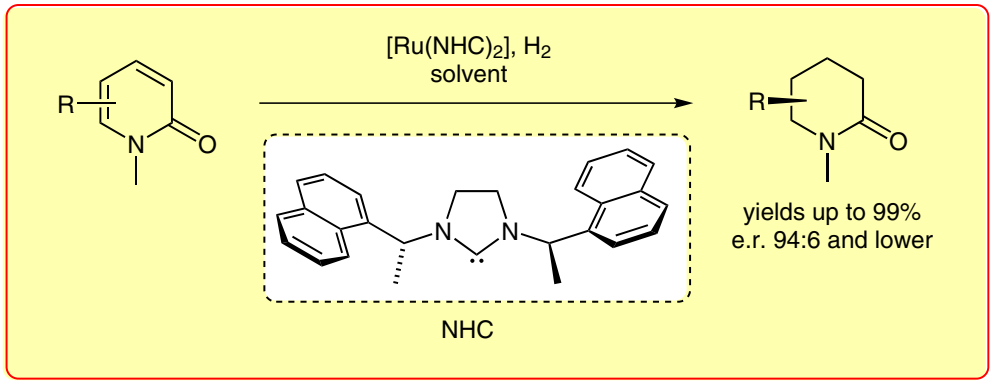

Received: 10.03 .2015

Accepted: 15.04.2015

Published online: 11.05 .2015

DOI: 10.1055/s-0034-1378703; Art ID: st-2015-b0171-I

Abstract An asymmetric homogeneous hydrogenation of $2(1 \mathrm{H})$-pyridones has been developed, using a ruthenium complex bearing two chiral N-heterocyclic carbene (NHC) ligands. To the best of our knowledge, the presented reaction is the first example of a homogeneous asymmetric conversion of 2-pyridones into the corresponding enantioenriched 2-piperidones.

Key words asymmetric catalysis, hydrogenation, NHC, piperidone, pyridone

Over the last couple of decades the asymmetric homogeneous hydrogenation of heterocyclic compounds has become a subject of growing interest for organic chemists. ${ }^{1}$ Conventional synthetic methods towards analogous enantioenriched saturated compounds possess several drawbacks which limit their attractiveness, particularly during the scaling up of the process. In most cases they require multi-step pathways including protecting group chemistry, complicated work-up and purification methods, and often superstoichiometric quantities of expensive chiral reagents. These entail lower overall yields and the production of significant amounts of chemical waste, contrary to the principles of green chemistry.

Asymmetric hydrogenation, on the other hand, makes use of a relatively environmentally benign and comparably very inexpensive reagent - molecular hydrogen $\left(\mathrm{H}_{2}\right)$. In combination with chiral metal-based catalysts at low loadings, asymmetric homogeneous hydrogenation comprises an elegant and attractive method for accessing enantioenriched multisubstituted cyclic or aliphatic compounds of high biological relevance. As such, it can allow for the shortening and simplification of synthetic routes towards complex enantioenriched molecules.
It is, however, of great importance to note that the asymmetric hydrogenation of heterocyclic compounds remains a very challenging process despite the progress achieved to date in this area. The major obstacle concerns the need to overcome the energy barrier imposed by aromaticity, which has generally resulted in the requirement for elevated pressures and reaction temperatures. Unfortunately, these may negatively affect the stereochemical outcome. Some elements, especially nitrogen and sulfur, tend to poison the catalysts and therefore completely shut down the process. Another problem that could cause a lowering of the enantioselectivity is the weaker coordination ability of simple unsaturated cyclic compounds, which in the absence of additional coordinating functional groups can ultimately hamper the face recognition of the starting material by the catalyst.

Growing demand for more efficient and selective methods to access valuable enantioenriched intermediates and fine chemicals has triggered the development of a wide range of interesting and impressive homogeneous catalytic systems for the asymmetric hydrogenation of various heterocyclic compounds. Since 1987, scientists have witnessed a great expansion of this area which reflected in a number of efficient methods for the asymmetric homogeneous hydrogenation of quinolines, ${ }^{2}$ isoquinolines, ${ }^{3}$ quinazolines, ${ }^{4}$ quinoxalines, ${ }^{5}$ pyridines, ${ }^{6}$ indoles/pyrroles, ${ }^{7}$ phenanthrolines, ${ }^{8}$ (benzo)thiophenes, ${ }^{9}$ (benzo)furans, ${ }^{10}$ indolizines, ${ }^{11}$ naphthyridines, ${ }^{12}$ and even carbocycles. ${ }^{13}$ By contrast, however, in the case of 2-pyridones, to the best of our knowledge, only heterogeneous hydrogenation reactions have been disclosed to date, with no examples offering asymmetric induction. Depending on the structure of the starting compounds, $\mathrm{Pd} / \mathrm{C}$ and $\mathrm{PtO}_{2}$ have been among the most often employed catalysts. ${ }^{14}$ 
We have recently reported on the development and application of a ruthenium(II)-based complex bearing chiral $\mathrm{N}$-heterocyclic carbene (NHC) ligands $\left[\mathrm{Ru}(\mathrm{SINpEt})_{2}\right]$. This privileged system has been successfully applied in the asymmetric hydrogenation reactions of a wide range of heterocycles: quinoxalines, ${ }^{13 b}$ benzofurans, ${ }^{10 f-g}$ (benzo)thiophenes, ${ }^{9 \mathrm{c}}$ flavones and chromones, ${ }^{15}$ indolizines, ${ }^{11}$ and furans. ${ }^{10 \mathrm{~h}}$ Inspired by these studies, we sought to investigate whether it would be possible to extend the unusually broad utility of this Ru-NHC complex to the asymmetric hydrogenation of various 2-pyridones.

At the outset of our study we performed the hydrogenation reaction on the readily available 6-methyl-2-pyridone (1). This compound was treated with the preformed $\mathrm{Ru}-$ $\mathrm{NHC}$ complex fformed in the reaction between [ $\mathrm{Ru}(2-\mathrm{Me}-$ allyl $)_{2}(\mathrm{cod})$ ], SINpEt. $\mathrm{HBF}_{4}$, and $\mathrm{KOt}$-Bu in $n$-hexane under a pressure of 70 bar of $\mathrm{H}_{2}$ at $60{ }^{\circ} \mathrm{C}$ for 24 hours. Unfortunately, no product was observed and only starting material was recovered (Table 1 , entry 1 ).

Table 1 Hydrogenation of the Unprotected Pyridone $\mathbf{1}^{\mathrm{a}}$

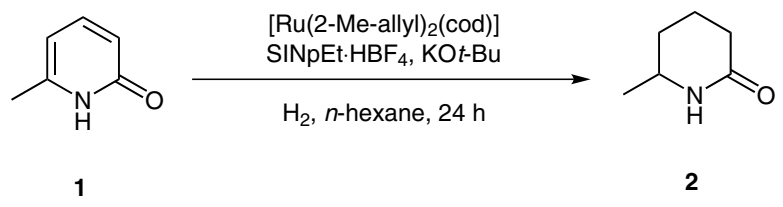

\begin{tabular}{llllll}
\hline Entry & Additive & $\begin{array}{l}\text { Pressure } \\
(\text { bar })\end{array}$ & $\begin{array}{l}\text { Temp } \\
\left({ }^{\circ} \mathrm{C}\right)\end{array}$ & $\begin{array}{l}\text { Conversion } \\
(\%)^{\mathrm{b}}\end{array}$ & e.r. $^{\mathrm{c}}$ \\
\hline 1 & - & 70 & 60 & - & $\mathrm{n} / \mathrm{d}$ \\
2 & $\mathrm{Et}_{3} \mathrm{~N}$ & 70 & 60 & - & $\mathrm{n} / \mathrm{d}$ \\
3 & $\mathrm{TFA}$ & 70 & 60 & - & $\mathrm{n} / \mathrm{d}$ \\
4 & - & 80 & 80 & $>99$ & $\mathrm{rac}$ \\
5 & $\mathrm{Et}_{3} \mathrm{~N}$ & 80 & 80 & $>99$ & $\mathrm{rac}$ \\
\hline
\end{tabular}

a General conditions: 1 (0.3 mmol), [Ru(2-Me-allyl) $\left.{ }_{2}(\mathrm{COD})\right](0.015 \mathrm{mmol})$, SINpEt. $\mathrm{HBF}_{4}(0.030 \mathrm{mmol}), \mathrm{KOt}$-Bu $(0.045 \mathrm{mmol})$, additive $(0.3 \mathrm{mmol}), \mathrm{H}_{2}$ n-hexane (1 mL), $24 \mathrm{~h}$; preformed complex was used.

b Determined by GC.

' Enantiomeric ratio was determined by GC on a chiral stationary phase.

The two additives tested, $\mathrm{Et}_{3} \mathrm{~N}$ and TFA, gave a negative result as well (Table 1 , entries 2 and 3 ). When the pressure of $\mathrm{H}_{2}$ was increased to 80 bar and the temperature to $80^{\circ} \mathrm{C}$, full conversion to the corresponding, although racemic, product 6-methyl-2-piperidone (2) was observed (Table 1, entry 4). A similar situation took place when $\mathrm{Et}_{3} \mathrm{~N}$ was used as an additive (Table 1 , entry 5 ). The reaction presumably proceeded through heterogeneous pathways as a precipitate of ruthenium black was observed in the reaction vessel.

Hypothesizing that the potential for lactam-lactim tautomerization could be responsible for the unsuccessful first attempts with 2-pyridone $\mathbf{1}$, we next examined the influ-

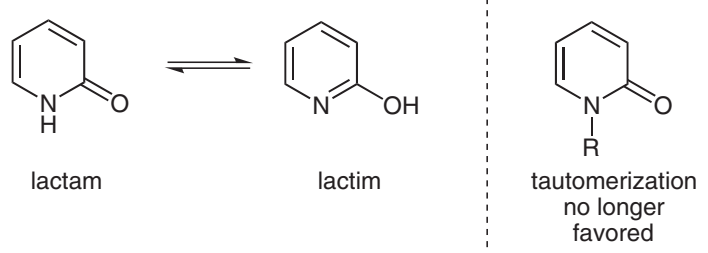

Scheme 1 Tautomerization of 2-pyridone

ence of various protecting groups of the $\mathrm{N}$ atom (Scheme 1). Among all the protecting groups tested, Bn, Ms, Ts, and Boc rendered the pyridone unreactive even at harsher conditions ( 80 bar of $\mathrm{H}_{2}, 80^{\circ} \mathrm{C}$ ). However, when a sterically less demanding methyl group was installed on the $\mathrm{N}$ atom of $\mathbf{1}$ (3a), hydrogenation was observed at 70 bar of $\mathrm{H}_{2}$ and $60{ }^{\circ} \mathrm{C}$, furnishing the corresponding product $4 \mathbf{a}$ with full conversion and a good enantiomeric ratio of 77:23. Encouraged by this result the two previously tested additives, $\mathrm{Et}_{3} \mathrm{~N}$ and TFA, were applied under the same conditions. While $\mathrm{Et}_{3} \mathrm{~N}$ was tolerated, it turned out that the catalytic system did not tolerate acidic conditions. A noticeable decrease in enantioselectivity was observed upon lowering the pressure to 10 bar, with the product $\mathbf{4 a}$ being obtained with an enantiomeric ratio of 68:32 (Table 2, entry 4). Further reaction parameter screening revealed that a combination of high pressure and lower temperature is beneficial for the stereochemical outcome. For example, at 120 bar of $\mathrm{H}_{2}$ and room temperature the enantiomeric ratio of the product $\mathbf{4 a}$ could be increased to 83:17 (Table 2, entry 8). Furthermore, in analogy to our previous projects concerning the asymmetric hydrogenation of heterocyclic compounds, the chiral ligand SINpEt.HBF 4 was again shown to be superior to all the other ligands tested in this study.

Next we analyzed the impact of other solvents on the reaction outcome. When $\mathrm{CH}_{2} \mathrm{Cl}_{2}$ was used as the reaction medium, only traces of racemic product were observed ( $8 \%$ conversion, Table 3 , entry 1 ). Benzene, toluene, and $\alpha, \alpha, \alpha-$ trifluorotoluene all allowed the reaction to proceed with very good enantioselectivity (e.r. $=83: 17$ to $86: 14$, Table 3, entries 2-4). The perfluorinated analog of toluene, however, completely inhibited the process (Table 3, entry 5). Surprisingly, full conversion was observed when pyridine was used as the solvent, although the enantiomeric ratio of the product 4a was somewhat lower. This could be attributed to a possible interaction of the nitrogen atom of pyridine with the metal center of the active catalyst, thus compromising the enantiorecognition of the substrate (Table 3, entry 6). Similar reasoning could explain the lower enantiomeric ratios observed with 1,4-dioxane and THF as the solvents, while $\mathrm{Et}_{3} \mathrm{~N}$ and $\mathrm{Et}_{2} \mathrm{O}$ did not interfere with the process, allowing for an enantiomeric ratio of 85:15 in both cases (Table 3, entries 7-10). Under the same conditions, the addition of $\mathrm{H}_{2} \mathrm{O}$ to THF drastically lowered the solubility of the 
Table 2 Screening of the Reaction Parameters ${ }^{\mathrm{a}}$

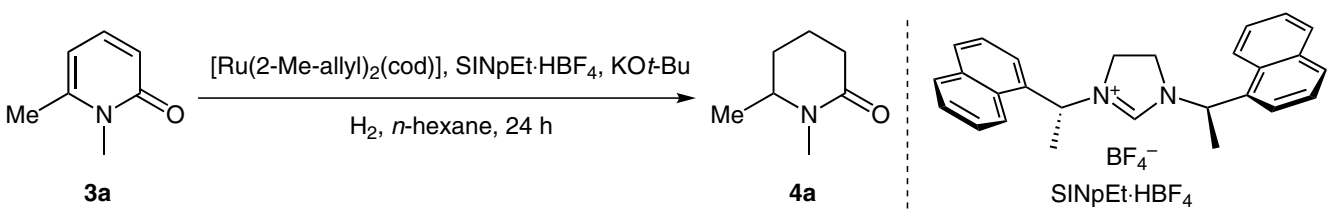

\begin{tabular}{llcccc}
\hline Entry & Additive & Pressure (bar) & Temp $\left({ }^{\circ} \mathrm{C}\right)$ & Conversion $(\%)^{\mathrm{b}}$ & e.r.c \\
\hline 1 & - & 70 & 60 & $>99$ & $77: 23$ \\
2 & $\mathrm{Et}_{3} \mathrm{~N}$ & 70 & 60 & $>99$ & $76: 24$ \\
3 & TFA & 70 & 60 & 37 & rac \\
4 & - & 10 & 60 & $>99$ & $68: 32$ \\
5 & - & 10 & 30 & $>99$ & $78: 22$ \\
6 & - & 80 & 50 & $>99$ & $75: 25$ \\
7 & - & 40 & 40 & $>99$ & $79: 21$ \\
8 & - & 120 & 25 & $>99$ & $83: 17$
\end{tabular}

\footnotetext{
a General conditions: $3 a(0.3 \mathrm{mmol}),\left[\mathrm{Ru}(2-\mathrm{Me}-\mathrm{allyl})_{2}(\mathrm{cod})\right](0.015 \mathrm{mmol}), \mathrm{SINpEt}_{\mathrm{HBF}}(0.030 \mathrm{mmol}), \mathrm{KOt}$-Bu (0.045 mmol), additive (0.3 mmol), $\mathrm{H}_{2}, \mathrm{n}$-hexane $(1 \mathrm{~mL}), 24 \mathrm{~h}$; preformed complex was used.

${ }^{b}$ Determined by ${ }^{1} \mathrm{H}$ NMR.

' Enantiomeric ratio was determined by GC on a chiral stationary phase.
}

reactant 3a, delivering only trace amounts of the product (Table 3, entry 11). The use of another protic solvent EtOH led to the formation of the racemic product (Table 3, entry 12). Presumably using this solvent, the catalyst underwent decomposition with release of catalytically highly active heterogeneous ruthenium nanoparticles. The cyclic analog of $n$-hexane, cyclohexane, did not change the reaction outcome, providing the product $\mathbf{4 a}$ with the same enantiomeric ratio of 83:17 (Table 3, entry 14). In contrast to the previously tested protic solvents, not only did the sterically hindered $t$-AmOH (2-methyl-2-butanol) allow for full conversion but also the enantioselectivity of the observed product was increased to 89:11 (Table 3, entry 14). Moreover, the enantiomeric ratio could be increased further to an impressive level of 94:6 upon lowering the reaction temperature to $-10{ }^{\circ} \mathrm{C}$. It is important to note that due to the high viscosity of $t$-AmOH at this temperature $n$-hexane was added as an innocent co-solvent.

With the optimized conditions in hand, we moved on to explore the scope of the reaction. A range of 2-pyridones substituted with sterically undemanding methyl or trifluoromethyl groups could be successfully hydrogenated to their corresponding products in a clean fashion with no side products being observed (Scheme 2). By exploring different substitution patterns for the methyl group, we found that the 3- and 6-methyl-substituted pyridones proved the best in terms of enantioselectivity. The model compound used in the screening studies, 6-methyl-2-pyridone (3a), was obtained with full conversion and a very high enantiomeric ratio of $94: 6$, although due to high volatility, only $50 \%$ of pure product was isolated after column chromatography.
Table 3 Solvent Screening

\begin{tabular}{|c|c|c|c|}
\hline Entry & Solvent & Conversion (\%) ${ }^{\mathrm{b}}$ & e.r..$^{c}$ \\
\hline 1 & $\mathrm{CH}_{2} \mathrm{Cl}_{2}$ & 8 & rac \\
\hline 2 & benzene & $>99$ & $83: 17$ \\
\hline 3 & toluene & $>99$ & $86: 14$ \\
\hline 4 & $\mathrm{PhCF}_{3}$ & $>99$ & $86: 14$ \\
\hline 5 & $\mathrm{C}_{6} \mathrm{~F}_{5} \mathrm{CF}_{3}$ & - & $\mathrm{n} / \mathrm{d}$ \\
\hline 6 & pyridine & $>99$ & $76: 24$ \\
\hline 7 & 1,4-dioxane & $>99$ & $79: 21$ \\
\hline 8 & THF & $>99$ & $75: 25$ \\
\hline 9 & $\mathrm{Et}_{3} \mathrm{~N}$ & $>99$ & $85: 15$ \\
\hline 10 & $\mathrm{Et}_{2} \mathrm{O}$ & $>99$ & $85: 15$ \\
\hline 11 & $\mathrm{H}_{2} \mathrm{O}-\mathrm{THF}(2: 1)$ & 6 & $\mathrm{rac}$ \\
\hline 12 & $\mathrm{EtOH}$ & $>99$ & $\mathrm{rac}$ \\
\hline 13 & $n$-hexane & $>99$ & $83: 17$ \\
\hline 14 & cyclohexane & $>99$ & $83: 17$ \\
\hline 15 & $t-\mathrm{AmOH}$ & $>99$ & $89: 11$ \\
\hline $16^{d}$ & $t$-AmOH- $n$-hexane $(1: 1)$ & $>99$ & $94: 6$ \\
\hline
\end{tabular}

a General conditions: $3 a(0.3 \mathrm{mmol})$, [Ru(2-Me-allyl) 2 (cod)] (0.015 mmol), SINpEt. $\mathrm{HBF}_{4}(0.030 \mathrm{mmol}), \mathrm{KOt}-\mathrm{Bu}(0.045 \mathrm{mmol}), \mathrm{H}_{2}$ (120 bar), solvent (1 $\mathrm{mL}), 25^{\circ} \mathrm{C}, 24 \mathrm{~h}$; preformed complex was used; solvent was exchanged prior to the reaction.

${ }^{\mathrm{b}}$ Determined by ${ }^{1} \mathrm{H}$ NMR.

' Enantiomeric ratio was determined by GC on a chiral stationary phase.

${ }^{d}$ Reaction run at $-10^{\circ} \mathrm{C}$. 

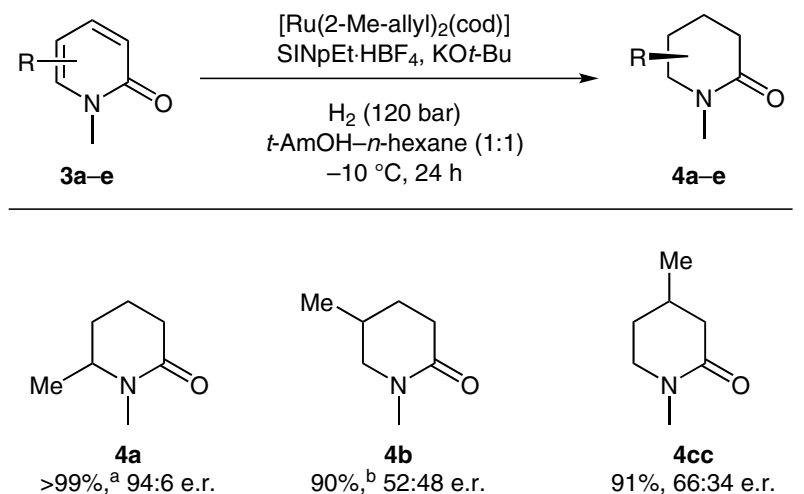<smiles>CC1CCCN(C)C1=O</smiles>

4d $82 \%,{ }^{b} 82: 18$ e.r.

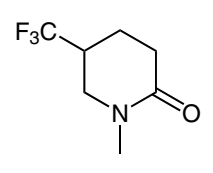

$88 \%, 54: 46$ e.r.
Scheme 2 Scope of the hydrogenation of the methyl- and trifluoro-

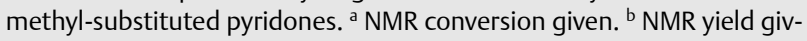
en. ${ }^{\mathrm{C}}$ Reaction run at $25^{\circ} \mathrm{C}$.

The 3-substituted analogue was converted into its corresponding product with a high yield of $82 \%$ and an enantiomeric ratio of $82: 18$. Contrary to any other examples, 4-methyl-2-pyridone (3c) required a higher reaction temperature $\left(25^{\circ} \mathrm{C}\right)$ in order to increase the enantioselectivity, furnishing the product $4 \mathbf{c}$ in $91 \%$ of yield and 66:34 enan- tiomeric ratio. The very same reaction run at sub-zero temperatures led otherwise to much lower enantiomeric ratio. In the case of 5-methyl-2-pyridone (3b) and 5-trifluoromethyl-2-pyridone (3e) the selectivities were much lower, although the yields remained within a high range of 88$90 \%$.

At this stage we turned our attention to pyridones substituted with aromatic rings of different electronic properties (Scheme 3). We envisaged that this substantial increase in bulkiness of the starting material may require reinvestigation of the reaction parameters. While 6-phenyl-2-pyridone (5a) could be quantitatively converted into the corresponding product at $-10{ }^{\circ} \mathrm{C}$ (57:43 e.r.), all the other phenyl-substituted pyridones reacted efficiently only at room temperature. The two other analogs of $\mathbf{5 a}$, that is, the pyridones bearing an electron-rich (5b) and -poor (5c) phenyl ring reacted with similarly good yields (73-75\%), albeit with low enantiomeric ratios. In comparison to 5-methyl2-pyridone (3b), the 5-aryl-substituted pyridones 5d-f were converted into their corresponding products with higher enantioselectivities, within enantiomeric ratio ranging from 73:27 to 70:30. 4-Phenyl-2-pyridone (5g) was quantitatively converted into the product $6 \mathbf{g}$ with a good enantiomeric ratio of 79:21, while 3-phenyl-2-pyridone $(\mathbf{5 h})$ delivered $\mathbf{6 h}$, albeit without a detectable level of enantioselectivity.

In conclusion, the first asymmetric homogeneous hydrogenation of 2-pyridones has been presented. The protocol described ${ }^{16}$ enables access to a range of different substitution patterns of enantioenriched 2-piperidones. However,

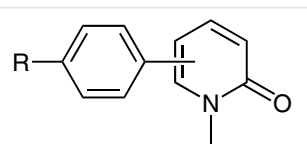

$5 \mathbf{a}-\mathbf{h}$

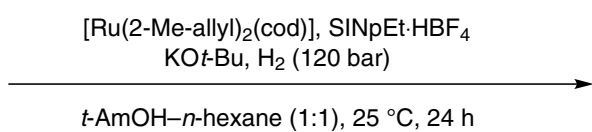

$t$-AmOH-n-hexane $(1: 1), 25^{\circ} \mathrm{C}, 24 \mathrm{~h}$

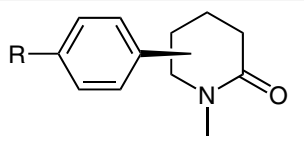

$6 a-h$<smiles>CN1C(=O)CCCC1c1ccccc1</smiles>

$6 a^{a, b}$

$99 \%, 57: 43$ e.r.<smiles>COc1ccc(C2CCC(=O)N(C)C2)cc1</smiles>

6 e<smiles>COc1ccc(C2CCCC(=O)N2C)cc1</smiles>

$6 b$

$73 \%, 58: 44$ e.r.<smiles>CN1CC(c2ccc(C(F)(F)F)cc2)CCC1=O</smiles>

$6 f$<smiles>CN1C(=O)CCCC1c1ccc(C(F)(F)F)cc1</smiles>

$6 c$

$75 \%$, 54:46 e.r.<smiles>CN1CCC(c2ccccc2)CC1=O</smiles>

$6 \mathbf{g}^{\mathrm{a}}$<smiles>CN1CC(c2ccccc2)CCC1=O</smiles>

$6 \mathrm{~d}^{\mathrm{a}}$

43\%, $73: 27$ e.r.

>99\%, 79:21 e.r.<smiles>CN1CCCC(c2ccccc2)C1=O</smiles>

$6 \mathrm{~h}$

$83 \%$, rac

Scheme 3 Scope of the hydrogenation of pyridones substituted with aromatic rings. ${ }^{\text {a }}$ Reaction run on a $0.5 \mathrm{mmol}$ scale. ${ }^{\mathrm{b}}$ Reaction run at $-10{ }^{\circ} \mathrm{C}$. 
while we are excited about this breakthrough, it is also clear that future studies should focus on improving the level of enantioselectivity.

\section{Acknowledgment}

We thank Dr. Matthew N. Hopkinson for helpful discussions during preparation of this manuscript. Generous financial support was provided by the Deutsche Forschungsgemeinschaft (Leibniz award). This work was supported by the NRW Graduate School of Chemistry in Münster (J.W.)

\section{Supporting Information}

Supporting information for this article is available online at http://dx.doi.org/10.1055/s-0034-1378703.

\section{References and Notes}

(1) For reviews on the hydrogenation of aromatic compounds, see: (a) Dyson, P. J. Dalton Trans. 2003, 2964. (b) Glorius, F. Org. Biomol. Chem. 2005, 3, 4171. (c) Zhou, Y.-G. Acc. Chem. Res. 2007, 40, 1357. (d) Kuwano, R. Heterocycles 2008, 76, 909. (e) Wang, D.-S.; Chen, Q.-A.; Lu, S.-M.; Zhou, Y.-G. Chem. Rev. 2012, 112, 2557. (f) Yu, Z.; Jin, W.; Jiang, Q. Angew. Chem. Int. Ed. 2012, 51, 6060. (g) Zhao, D.; Glorius, F. Angew. Chem. Int. Ed. 2013, 52, 9616.

(2) For selected examples of asymmetric hydrogenation of quinolines, see: (a) Wang, W.-B.; Lu, S.-M.; Yang, P.-Y.; Han, X.-W.; Zhou, Y.-G. J. Am. Chem. Soc. 2003, 125, 10536. (b) Rueping, M.; Antonchick, A. P.; Theissmann, T. Angew. Chem. Int. Ed. 2006, 45, 3683. (c) Zhou, H.-F.; Li, Z.-W.; Wang, Z.-J.; Wang, T.-L.; Xu, L.-J.; He, Y.-M.; Fan, Q.-H.; Pan, J.; Gu, L.-Q.; Chan, A. S. C. Angew. Chem. Int. Ed. 2008, 47, 8464. (d) Guo, Q.-S.; Du, D.-M.; Xu, J. Angew. Chem. Int. Ed. 2008, 47, 759. (e) Wang, T.-L.; Zhuo, L.-G.; Li, Z.-W.; Chen, F.; Ding, Z.-Y.; He, Y.-M.; Fan, Q.-H.; Xiang, J.-F.; Yu, Z.-X.; Chan, A. S. C. J. Am. Chem. Soc. 2011, 133, 9878. (f) Chen, Q.-A.; Gao, K.; Duan, Y.; Ye, Z.-S.; Shi, L.; Yang, Y.; Zhou, Y.-G. J. Am. Chem. Soc. 2012, 134, 2442. (g) Zhang, D.-Y.; Yu, C.B.; Wang, M.-C.; Gao, K.; Zhou, Y.-G. Tetrahedron Lett. 2012, 53, 2556. (h) Maj, A. M.; Suisse, I.; Méliet, C.; Hardouin, C.; Agbossou-Niedercorn, F. Tetrahedron Lett. 2012, 53, 4747. (i) Chen, Z.-P.; Ye, Z.-S.; Chen, M.-W.; Zhou, Y.-G. Synthesis 2013, 45, 3239. (j) Cai, X.-F.; Huang, W.-X.; Chen, Z.-P.; Zhou, Y.-G. Chem. Commun. 2014, 50, 9588.

(3) For examples of asymmetric hydrogenation of isoquinolines, see: (a) Lu, S.-M.; Wang, Y.-Q.; Han, X.-W.; Zhou, Y.-G. Angew. Chem. Int. Ed. 2006, 45, 2260. (b) Shi, L.; Ye, Z.-S.; Cao, L.-L.; Guo, R.-N.; Hu, Y.; Zhou, Y.-G. Angew. Chem. Int. Ed. 2012, 51, 8286. (c) Iimuro, A.; Yamaji, K.; Kandula, S.; Nagano, T.; Kita, Y.; Mashima, K. Angew. Chem. Int. Ed. 2013, 52, 2046. (d) Ye, Z.-S.; Guo, R.-N.; Cai, X.-F.; Chen, M.-W.; Shi, L.; Zhou, Y.-G. Angew. Chem. Int. Ed. 2013, 52, 3685. (e) Kita, Y.; Yamaji, K.; Higashida, K.; Sathaiah, K.; Iimuro, A.; Mashima, K. Chem. Eur. J. 2015, 21, 1915.

(4) Kita, Y.; Higashida, K.; Yamaji, K.; Iimuro, A.; Mashima, K. Chem. Commun. 2015, 51, 4380

(5) For selected examples of asymmetric hydrogenation of quinoxalines, see: (a) Murata, S.; Sugimoto, T.; Matsuura, S. Heterocycles 1987, 26, 763. (b) Bianchini, C.; Barbaro, P.; Scapacci, G.;
Farnetti, E.; Graziani, M. Organometallics 1998, 17, 3308. (c) Bianchini, C.; Barbaro, P.; Scapacci, G. J. Organomet. Chem. 2001, 621, 26. (d) Qiu, L.; Kwong, F. Y.; Wu, J.; Lam, W. H.; Chan, S.; Yu, W.-Y.; Li, Y.-M.; Guo, R.; Zhou, Z.; Chan, A. S. C. J. Am. Chem. Soc. 2006, 128, 5955. (e) Tang, W.; Xu, L.; Fan, Q.-H.; Wang, J.; Fan, B.; Zhou, Z.; Lam, K.-H.; Chan, A. S. C. Angew. Chem. Int. Ed. 2009, 48, 9135. (f) Mršić, N.; Jerphagnon, T.; Minnaard, A. J.; Feringa, B. L.; de Vries, J. G. Adv. Synth. Catal. 2009, 351, 2549. (g) Rueping, M.; Tato, F.; Schoepke, F. R. Chem. Eur. J. 2010, 16, 2688. (h) Cartigny, D.; Nagano, T.; Ayad, T.; Genêt, J. P.; Ohshima, T.; Mashima, K.; Ratovelomanana-Vidal, V. Adv. Synth. Catal. 2010, 352, 1886. (i) Wang, D.-W.; Wang, D.S.; Chen, Q.-A.; Zhou, Y.-G. Chem. Eur. J. 2010, 16, 1133. (j) Chen, Q.-A.; Wang, D.-S.; Zhou, Y.-G.; Duan, Y.; Fan, H.-J.; Yang, Y.; Zhang, Z. J. Am. Chem. Soc. 2011, 133, 6126. (k) Cartigny, D.; Berhal, F.; Nagano, T.; Phanasavath, P.; Ayad, T.; Genêt, P.; Ohshima, T.; Mashima, K.; Ratovelomanana-Vidal, V. J. Org. Chem. 2012, 77, 4544.

(6) For selected examples of hydrogenation of pyridines, see: (a) Glorius, F.; Spielkamp, N.; Holle, S.; Goddard, R.; Lehmann, C. W. Angew. Chem. Int. Ed. 2004, 43, 2850. (b) Ye, Z.-S.; Chen, M.-W.; Chen, Q.-A.; Shi, L.; Duan, Y.; Zhou, Y.-G. Angew. Chem. Int. Ed. 2012, 51, 10181.

(7) For recent examples of asymmetric hydrogenation of indoles/pyrroles, see: (a) Kuwano, R.; Sato, K.; Kurokawa, T.; Karube, D.; Ito, Y. J. Am. Chem. Soc. 2000, 122, 7614. (b) Kuwano, R.; Kaneda, K.; Ito, T.; Sato, K.; Kurokawa, T.; Ito, Y. Org. Lett. 2004, 6, 2213. (c) Kuwano, R.; Kashiwabara, M. Org. Lett. 2006, 8, 2653. (d) Kuwano, R.; Kashiwabara, M.; Ohsumi, M.; Kusano, H. J. Am. Chem. Soc. 2008, 130, 808. (e) Mršić, N.; Jerphagnon, T.; Minnaard, A. J.; Feringa, B. L.; de Vries, J. G. Tetrahedron: Asymmetry 2010, 21, 7. (f) Baeza, A.; Pfaltz, A. Chem. Eur. J. 2010, 16, 2036. (g) Wang, D.-S.; Chen, Q.-A.; Li, W.; Yu, C.-B.; Zhou, Y.-G.; Zhang, X. J. Am. Chem. Soc. 2010, 132, 8909. (h) Wang, D.-S.; Tang, J.; Zhou, Y.-G.; Chen, M.-W.; Duan, Y.; Jiang, G.-F. Chem. Sci. 2011, 2, 803. (i) Duan, Y.; Chen, M.-W.; Ye, Z.-S.; Wang, D.-S.; Chen, Q.-A.; Zhou, Y.-G. Chem. Eur. J. 2011, 17, 7193. (j) Wang, D.-S.; Ye, Z.-S.; Chen, Q.-A.; Zhou, Y.-G.; Yu, C.-B.; Fan, H.-J.; Duan, Y. J. Am. Chem. Soc. 2011, 133, 8866. (k) Duan, Y.; Chen, M.-W.; Chen, Q.-A.; Yu, C.-B.; Zhou, Y.-G. Org. Biomol. Chem. 2012, 10, 1235. (l) Duan, Y.; Li, L.; Chen, M.-W.; Yu, C.-B.; Fan, H.-J.; Zhou, Y.-G. J. Am. Chem. Soc. 2014, 136, 7688.

(8) Wang, T.; Chen, F.; Qin, J.; He, Y.-M.; Fan, Q.-H. Angew. Chem. Int. Ed. 2013, 52, 7172.

(9) For selected examples of hydrogenation of (benzo)thiophenes, see: (a) Bianchini, C.; Meli, A. Acc. Chem. Res. 1998, 31, 109. (b) Borowski, A. F.; Sabo-Etienne, S.; Donnadieu, B.; Chaudret, B. Organometallics 2003, 22, 4803. (c) Urban, S.; Beiring, B.; Ortega, N.; Paul, D.; Glorius, F. J. Am. Chem. Soc. 2012, 134, 15241.

(10) For selected examples of hydrogenation of (benzo)furans, see: (a) Ohta, T.; Miyake, T.; Seido, N.; Kumobayashi, H.; Takaya, H. J. Org. Chem. 1995, 60, 357. (b) Studer, M.; Wedemeyer-Exl, C.; Spindler, F.; Blaser, H.-U. Monatsh. Chem. 2000, 131, 1335. (c) Maris, M.; Huck, W.-R.; Mallat, T.; Baiker, A. J. Catal. 2003, 219, 52. (d) Kaiser, S.; Smidt, S. P.; Pfaltz, A. Angew. Chem. Int. Ed. 2006, 45, 5194. (e) Feiertag, P.; Albert, M.; Nettekoven, U.; Spindler, F. Org. Lett. 2006, 8, 4133. (f) Ortega, N.; Urban, S.; Beiring, B.; Glorius, F. Angew. Chem. Int. Ed. 2012, 51, 1710. (g) Ortega, N.; Beiring, B.; Urban, S.; Glorius, F. Tetrahedron 2012, 68, 5185. (h) Wysocki, J.; Ortega, N.; Glorius, F. Angew. Chem. Int. Ed. 2014, 53, 8751. (i) Pauli, L.; Tannert, R.; Scheil, R.; Pfaltz, A. Chem. Eur. J. 2015, 21, 1482. 
(11) Ortega, N.; Tang, D.-T. D.; Urban, S.; Zhao, D.; Glorius, F. Angew. Chem. Int. Ed. 2013, 52, 9500.

(12) Zhang, J.; Chen, F.; He, Y.-M.; Fan, Q.-H. Angew. Chem. Int. Ed. 2015, 54, 4622.

(13) For the asymmetric arene hydrogenation, see: (a) Urban, S.; Ortega, N.; Glorius, F. Angew. Chem. Int. Ed. 2011, 50, 3803. (b) Kuwano, R.; Morioka, R.; Kashiwabara, M.; Kameyama, N. Angew. Chem. Int. Ed. 2012, 51, 4136.

(14) Selected examples of heterogeneous hydrogenation reactions of 2-pyridones: (a) Hartmann, R. W.; Reichert, M.; Göhring, S. Eur. J. Med. Chem. 1994, 29, 807. (b) Hartmann, R. W.; Reichert, M. Arch. Pharm. 2000, 333, 145. (c) Padwa, A.; Heidelbaugh, T. M.; Kuethe, J. T. J. Org. Chem. 2000, 65, 2368.

(15) Zhao, D.; Beiring, B.; Glorius, F. Angew. Chem. Int. Ed. 2013, 52, 8454.

(16) General Procedure for the Asymmetric Hydrogenation In a glovebox, $\left[\mathrm{Ru}(2-\mathrm{Me}-\text { allyl })_{2}(\mathrm{cod})\right](4.8 \mathrm{mg}, 0.015 \mathrm{mmol})$, SINpEt $\cdot \mathrm{HBF}_{4}(14.5 \mathrm{mg}, 0.031 \mathrm{mmol})$ and dry KOt-Bu $(5.0 \mathrm{mg}$, $0.045 \mathrm{mmol}$ ) were placed in a flame-dried screw-capped Schlenk tube equipped with a magnetic stirring bar. The mixture was suspended in $0.5 \mathrm{~mL}$ of hexane and stirred at $70{ }^{\circ} \mathrm{C}$ for $16 \mathrm{~h}$ after which $t-\mathrm{AmOH}(0.5 \mathrm{~mL})$ was added and stirred at r.t. for $1 \mathrm{~h}$. The resulted mixture was transferred under argon to a glass vial containing a 2-pyridone $(0.3 \mathrm{mmol})$ and a magnetic stirring bar. Any applied additive $(0.3 \mathrm{mmol})$ was added at this point. The glass vial was placed in a $150 \mathrm{~mL}$ stainless-steel reactor, and the $\mathrm{H}_{2}$ pressure was set at 120 bar. The hydrogenation reaction was performed at the indicated temperature for $24 \mathrm{~h}$. The crude post-reaction mixture was filtered through a plug of silica using $5 \% \mathrm{MeOH}$ in $\mathrm{CH}_{2} \mathrm{Cl}_{2}$ followed by flash column chromatography ( $5 \% \mathrm{MeOH}$ in $\mathrm{CH}_{2} \mathrm{Cl}_{2}$ ). The enantiomeric ratio of all compounds was determined by chiral GC or HPLC.

Compound 4a: ${ }^{1} \mathrm{H}$ NMR $\left(300 \mathrm{MHz}, \mathrm{CDCl}_{3}\right): \delta=3.46(\mathrm{~h}, J=6.4 \mathrm{~Hz}$, $1 \mathrm{H}), 2.92(\mathrm{~s}, 3 \mathrm{H}), 2.37$ (t, J = 6.5 Hz, $2 \mathrm{H}), 1.99-1.78(\mathrm{~m}, 2 \mathrm{H})$, 1.76-1.54 (m, $2 \mathrm{H}), 1.23$ (d, $J=6.5 \mathrm{~Hz}, 3 \mathrm{H}) .{ }^{13} \mathrm{C}$ NMR $(75 \mathrm{MHz}$, $\left.\mathrm{CDCl}_{3}\right): \delta=170.45,54.47,33.05,32.21,30.25,19.95,17.86$. ESIMS: $m / z$ calcd for $\left[\mathrm{C}_{7} \mathrm{H}_{13} \mathrm{NONa}\right]^{+}: 150.0889$; found: 150.0889 . FTIR (ATR): 1620, 1447, 1397, 1335, 1308, 1246, 1184, 1138, 1099, 1053, 1026, 910, 853, 691, $648 \mathrm{~cm}^{-1}$. 